\title{
Yeni Doğan Buzağılarda Karşılaşılan Femur Kırığı Olgularının Lokalizasyonu, Şekli ve Sağaltım Seçeneklerinin Değerlendirilmesi

\author{
Celal Şahin ERMUTLU1*
}

\author{
${ }^{1}$ Kafkas Üniversitesi Veteriner Fakültesi Cerrabi Anabilim Dal, Kars, TÜRKIYYE
}

*Corresponding author e-mail: sahinermutlu@hotmail.com

\begin{abstract}
ÖZ
Bu çalışmada 2017 yllında Kafkas Üniversitesi Veteriner Fakültesi Hayvan Sağlı̆ı Eğitim, Araştırma ve Uygulama Hastanesine femur kırı̆̆ şikâyeti ile getirilen buzağılarda kırık oluşum nedeni, kırığın lokalizasyonu ve sağaltım yöntemleri ile sonuçlarının değerlendirilmesi amaçlandı. Hayvan materyalini farklı cins ve ırklara ait 13 adet yeni doğan buzağı oluşturdu. Kırık etiyolojileri belirlendikten sonra kırık lokalizasyonu ve tipi saptanarak yapılacak sağaltım yöntemi planlandı. Operasyonlar subaraknoid anestezi altında gerçekleștirildi. Kırık fiksasyonu için 9 olguda retrograd pin, 1 olguda plaka uygulaması gerçekleştirildi. Yeni doğan buzağılarda kırı̆̆ın en çok (\%53.84) güç doğuma bağlı bilinçsiz yaklaşım veya kriko kullanımına bağl1 geliştiği tespit edildi. Suprakondüler ve orta diafizer oblik kırıkların eşit oranda ve diğer kırık tiplerine göre daha yaygın (\%30.76) görüldüğü belirlendi. Buzağıların postoperatif dönemde kısa süre (2.3 gün) içerisinde ilgili ekstremitelerini kullandıkları görüldü. Yeni doğan buzağılarda karşılaşılan femur kırıklarının tedavisinde intramedullar pinleme ile $\% 88.88$ oranında başanı elde edilebileceği tespit edildi.
\end{abstract}

Anahtar Kelimeler: Buzağı, Femur kırıkları, Sağaltım

\section{Assessment of Localization, Shape and Treatment Options of Femur Fracture Cases in Newborn Calves}

\begin{abstract}
In this study, it was aimed to evaluate the results of fracture formation, fracture localization and treatment methods and results of the fractures brought to the Hospital of Kafkas University Faculty of Veterinary Medicine Research and Practice Hospital between 2017 by complaint of femur fracture. The animal material consisted of 13 newborn calves belonging to different sex and breeds. After the etiology of the fractures, the localization of the fracture and type was determined, treatment were planned. Operations were performed under subarachnoid anesthesia. For fracture fixation, 1t was conducted in 9 cases retrograde pin and 1 case of plate application. It was found that the most developed (53.84\%) of the fractures in newborn calves were due to forced extraction during dystocia. Supracondylar and mid diafizer oblique fractures were found equally and more common $(30.76 \%)$ in comparison with other types of fractures. It was observed that the calves used the relevant limbs within a short period of time (2.3 days) in the postoperative period. In the treatment of femur fractures encountered in newborn calves, intramedullary pinning was found to be a success rate of $88.88 \%$.
\end{abstract}

Key Words: Calf, femur fractures, treatment.

To cite this article: Ermutlu C. Ş. Yeni Doğan Buză̆zlarda Karşılaşılan Femur Kınğı Olgularmm Lokalizasyonu, Şekli ve Sağaltım Seçeneklerinin Değerlendirilmesi Kocatepe Vet J. (2018) 11(3): 279-285. 


\section{GİRİŞ}

Buzağılar yeni doğan dönemlerinde enfeksiyöz ve non efeksiyöz olarak birçok hastalığa maruz kalırlar. Travma kemiklerde kırık oluşumunda rol oynayan en önemli non enfeksiyöz faktörlerden biridir (Akin 2014, Nichols ve ark. 2010). Yeni doğan buzağılarda güç doğuma bağlı olarak yapılan hatalı girişimler (Aksoy ve ark. 2009, Arıcan ve ark. 2013, Ferguson ve ark. 1990, Ferguson 1994, Nichols ve ark. 2010) ile doğum sonrasında diğer hayvanlar tarafindan tekmelenme, annenin yavrunun ekstremitelerine basmas1, kayma ve düşme (Akin 2014, Arıcan ve ark. 2013, Bilgili ve ark. 1999, Durmuş ve ark. 2009, Yanmaz ve ark. 2014), transport ve trafik kazalar1 (Akin 2014, Yanmaz ve ark. 2014) gibi nedenler k1r1k oluşumuna yol açmaktadır. Buzağılarda kırıklar en çok metakarpusta bunu izleyerek de femurda şekillenmektedir (Akin 2014, Durmuş ve ark. 2009, Ferguson ve ark. 1990, Hoederman ve ark. 2012).

Yeni doğan buzağılarda karşılaşılan femur kırıkları çoğunlukla proksimal epifiz ve distal metafizde şekillenmekte olup genellikle transversal ve oblik kırıklar biçimindedir. Fragmentlerin tamamen yer değiştirmesi, periostun tamamen siyrilması ve komşu dokulardaki yaralanmalar tipik olarak görülen bozukluklardır (Hoederman ve ark. 2012).

Cerrahi tekniklerin gelişmesi, veteriner cerrahi alanında sığırlara yapılan ortopedik girişimleri daha tercih edilebilir hale getirmiştir (Ferguson ve ark. 1990) ancak kır1k tedavisi yapilmadan önce hayvanin genetik potansiyelinin, ekonomik değerinin ve kırık tipi ile lokalizasyonunun değerlendirilmesi gereklidir (Görgül ve ark. 2004). Kırk iyileşmesi, kırık hattındaki hareketin derecesi, bakteriyal kontaminasyonun varllğı, yumuşak doku yaralanmalarının şiddeti, kırı tipi ve lokalizasyonu, genel sağlık durumu ile hastanın yaşı gibi faktörler tarafindan etkilenmektedir (Aithal ve ark. 2004, Gangl ve ark. 2006).

Femurda konservatif tedavi ile başarılı sonuçlar alınma olasıllğı oldukça düşüktür. Thomas splint ya da intra-medullar pin uygulamaları sağaltım amacıyla kullanıldığında distal metafizdeki kırıklara göre diafizer kırıklarda olumlu sonuçlar alma şansı daha yüksektir. Distal metafizyal kırikların fiksasyonu için kullanılan steinman pinler migrasyon ve instabilite ile sonuçlanmaktadır. Plaka osteosentezi ile yapılan sağaltım kırık lokasyonu tarafından etkilenmez. Yeni doğan buzağılarda femoral kemiğin yumuşak olması plaka osteosentezindeki en büyük olumsuzluklardandır. Çünkü yumuşak neonatal kemik, vida gevşemesine predispozisyon yaratabilir ve sonrasinda fiksasyonda instabilite ile karşılaşılabilir (Hoederman ve ark. 2012). Yeni doğan buzağıların femur kırıklarında sağaltım amacıyla kullanılan intermedullar interloking pinleme tekniğinin prognozu k1rk lokasyonu ne olursa olsun iyi olduğu bildirilmiştir (Bellon ve Mulon 2011, Hoederman ve ark. 2012, Junior ve ark. 2010).

$\mathrm{Bu}$ çalıșmanın amac1 yeni doğan buzağılarda karşılaşılan femur kırıklarının etiyolojileri ile lokalizasyonlarının belirlenmesi ve sağalım sonuçlarının aktarılmasıdır.

\section{MATERYAL ve METOT}

Çalışma materyalini 2017 yılında Kafkas Üniversitesi Veteriner Fakültesi Hayvan Hastanesi Cerrahi Kliniği’ne arka ekstremite topallığ1 şikâyeti ile getirilen ve femur kırrğı tespit edilen farklı 1rk, yaş ve cinsiyetten 18 adet buzağıdan kaput ve kollum femoris kırığı olan 5 adet buzağı hariç 13 adet buzağı oluşturdu. 13 buzağıdan 10 tanesine tedavi uygulanırken, 3 tanesine hayvan sahiplerinin tedaviyi kabul etmemesinden dolayı sağaltım uygulanmadı. Kırık lokalizasyonları ve tiplerinin de araştırıldığ bu çalışmada tedavi edilmeyen bu 3 olguya da yer verildi.

Hasta sahiplerinden alinan anamnez bilgileriyle kır1k etiyolojileri belirlendi. Elde edilen verilerin dağılımı yüzde olarak ifade edildi. Klinik ve radyografik muayenelerden sonra kirik lokalizasyonu ve tipi saptanarak yapılacak sağaltım yöntemi planlandı. Hastalarda preoperatif hazırlıklar tamamlandıktan sonra ilgili bölgenin tıraş ve dezenfeksiyonu yapıld1. Anestezi yöntemi olarak subaraknoid anestezi tercih edildi. Operasyon masasına 30 derecelik eğim verildi. Hastanın kranial kısmı yüksekte ve kırık ekstremite yukarıda kalacak biçimde lateral pozisyonda yatırlan hasta operasyon masasına sabitlendi. Lumbosakral bölge enjeksiyon amaciyla hazırlandiktan sonra deri ve deri altı dokuların infiltrasyon yöntemi ile lokal anestezisi sağlandı ve 25 gouge $\left(\right.$ Egemen $^{\circledR}$ anestezi iğnesi) spinal iğne ile lumbosakral aralığa girildi. BOS sıvisı gelişi ile subaraknoid bölgeye ulaşıldığ doğrulandıktan sonra $0.02 \mathrm{mg} / \mathrm{kg}$ dozunda ropivacaine $\mathrm{HCl} \quad$ Naropin $^{\circledR} \quad 10 \mathrm{~mL}$ amp., AstraZeneca, Germany) $0.5 \mathrm{~mL} /$ dak hizında enjekte edildi. Ekstremitelere yapılan derin ağr1 duyusu testi ve pink prik uygulamalarıyla ağr1 duyusunun ortadan kalkttğ belirlendi ve anestezik ajan uygulamas1 sonlandırıldi. Kır1k hattına kraniyolateral olarak yaklaşıldı. Kırık bacağın lateral yüzeyi proksimalde trochanter majörden distalde femurun lateral epikondilüsüne kadar ensize edildi. Muskulus tensor fasiya lata künt diseksiyon ile ayrıldı. Femura ulaşmak için muskulus vastus lateralis ile biseps femoris kasları sinır boyunca ayırt edildi. Biseps femoris kası kaudal, vastus lateralis kas1 ise kraniyal yönde ekarte edildi. Kırık bölgesine ulaşıldıktan sonra kırrk hematomu aspire edildi ve kırık bölgesi $0.9 \% \mathrm{NaCl}$ ile yıkandı. Kırık fragmentlerinin uçları kemik tutma pensleri yardımıyla kırık bölgesinden dışarı alınarak 7 olguda 
retrograd pin, 2 olguda ise çapraz pin uygulaması gerçekleştirildi. Bu olgularda 4 mm'lik ve 2 mm'lik pinler kombine olarak kullanıldı. Bir olguda ise geçici stabilizasyon kemik tutma pensleri ile sağlandıktan sonra $4 \mathrm{~mm}$ kalınlığında plaka ve 3 adet $3 \mathrm{~mm}$ ' lik ile 3 adet de $4.5 \mathrm{~mm}$ ' lik vida kullanılarak kalıcı fiksasyon sağlandı. Operasyon bölgesi rutin olarak kapatıld1. Operasyonlardan sonra kontrol grafileri alınd. Hastalar aynı gün taburcu edildi ve postoperatif profilaksi amaciyla sefazolin sodyum (1 g/12 saat, IM 5 gün) ve analjezi amaciyla meloxicam ( $2 \mathrm{mg} / \mathrm{kg}, \mathrm{IM}, 3$ gün) önerildi. İlk hafta her gün sonrasinda 15' er gün arayla olmak üzere hasta sahipleri telefonla aranarak buzağıların durumu öğrenildi. Klinik ve radyografik kontroller için hasta sahiplerinin tamamı 15' er günlük periyotlarda hastaneye çağrılmasına rağmen yalnızca 4 tanesi kontrol için hastasını getirdi. Diğer olguların durumları telefonla bilgi alınarak öğrenildi. Osteosentez sonrası buzağılara bandaj uygulanmad1. Hayvan sahiplerine buzağıları dar bir alanda bakması ve hareket k1sitlaması önerildi. Buzağıların ilgili ekstremite üzerine yük bindirdikleri gün ekstremiteyi kullandıkları gün olarak kabul edildi.

\section{BULGULAR}

Olguların 1rk, yaş cinsiyet, kırık lokalizasyonu, sağaltım seçenekleri ve sonuçları Tablo 1'de veriliştir. Hayvanların 1rklara göre dağılımı Simental 7, Esmer 3, Esmer-Simental melezi 2 ve EsmerDoğu Anadolu Kırmızısı melezi 1 olarak belirlenirken, olguların 9'u dişi 4'ü erkekti. Hastaların ortalama yaşları 26.69 (min: 1, max: 180) gün olarak saptandı. Olgularda karşılaşılan kırık sebepleri 7 tanesinde güç doğum (\%53.84), 3 tanesinde düşme $(\% 23,87), 1$ tanesinde mazgal arasına sıkışma $(\% 7,69), 1$ tanesinde tekmelenme
$(\% 7,69)$ ve birinde de $(\% 7,69)$ annenin yavrunun ekstremitesine basmasi olarak belirlendi. Kirık lokalizasyonu ve şekli incelendiğinde ise olguların 4' ünde suprakondüler k1r1k $(\% 30,76)$, 4' ünde orta diafizer oblik kırık $(\% 30,76)$, 2'sinde orta parçalı diafizer kırık $(\% 15,38), 2$ ' sinde distal diafizer oblik kirik(15,38), 1' inde ise orta diafizer transversal kır1k $(\% 7,69)$ saptand 1 (Tablo 1).

Olgulardan 3'üne hasta sahipleri istemediği için operasyon yapilmad1, kalan 10 olgudan 7'sinde intra medullar pinleme (Resim 1), 2'sinde çapraz pinleme yapılırken, 1 olguda plak uygulaması gerçekleştirildi. Operasyon sonrasi hastalarin ekstremitelerini kullandıkları ortalama gün 2.3 (min: 1 gün, max: 4) gün olarak belirlendi. Post-operatif dönemde 1 hasta sahibine ulaşılamazken, diğer hasta sahiplerinden telefonla bilgi alındi. Baz1 hasta sahipleri ise hastalarını getirerek pinleri çıkartıldı. Olguların post operatif en kısa 2 ay süre ve en uzun 11 aylık sürede kontrolleri yapıldı. Bu süreler zarfinda 1, 3, 4, 7, 9, 10, 11, 12 numaralı olgular tamamen iyileşirken, 2 numaralı olgunun 15. günde yapilan muayenesinde saptanan enfeksiyon nedeniyle ötenazi kararı verildi. Hastalardan 13 nolu olguda post operatif 15. günde vidaların gevşediği ve distal kırı̆̆ın iyileşmediği saptandı (Resim 2). Bu olguda hasta sahibi yeniden operasyonu kabul etmedi ve hasta kendi haline birakıld1. Post-operatif 35. günde tekrar kontrolü yapılan hastada kaynamanın anormal olduğu ve topallığın devam ettiği belirlenerek plaka çıkartıldı. Plaka osteosentezi yapilan olgu, intramedullar pinleme tekniği ile karşılaştırma amacından ziyade hem kirik lokalizasyonunun hem de kirık etiyolojisinin belirlenmesinde veri oluşturması sebebiyle çalışmaya dahil edildi. Hasta sahipleri 5, 6 ve 8 nolu olgularda sağaltımı kabul etmedi.
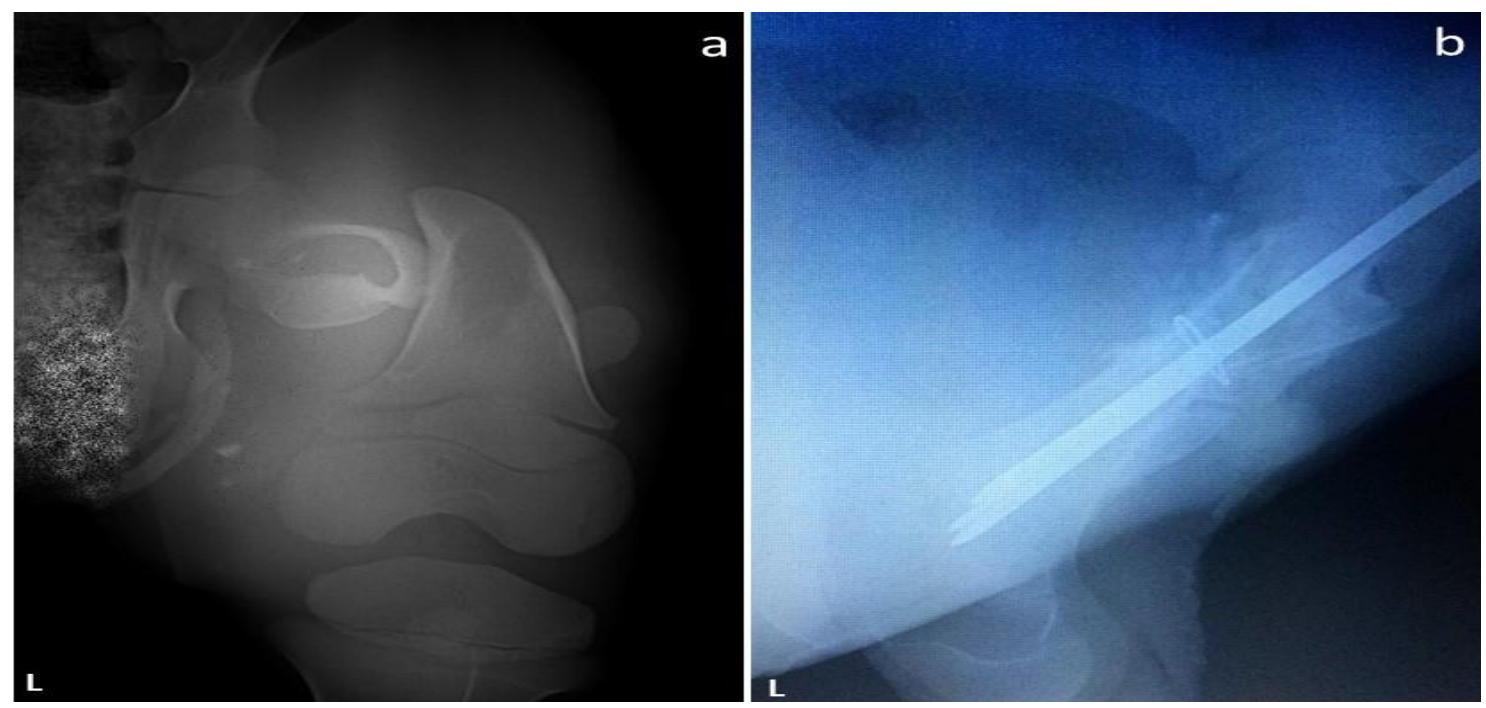

Resim 1. 7 Numaralı olguya ait radyografik görüntüler. (a. Operasyon öncesi, b. Operasyon sonrası 15. gün) Figure 1. Radigrahic view of case 7 (a. Preoperatively, b. Postoperative 15. day) 


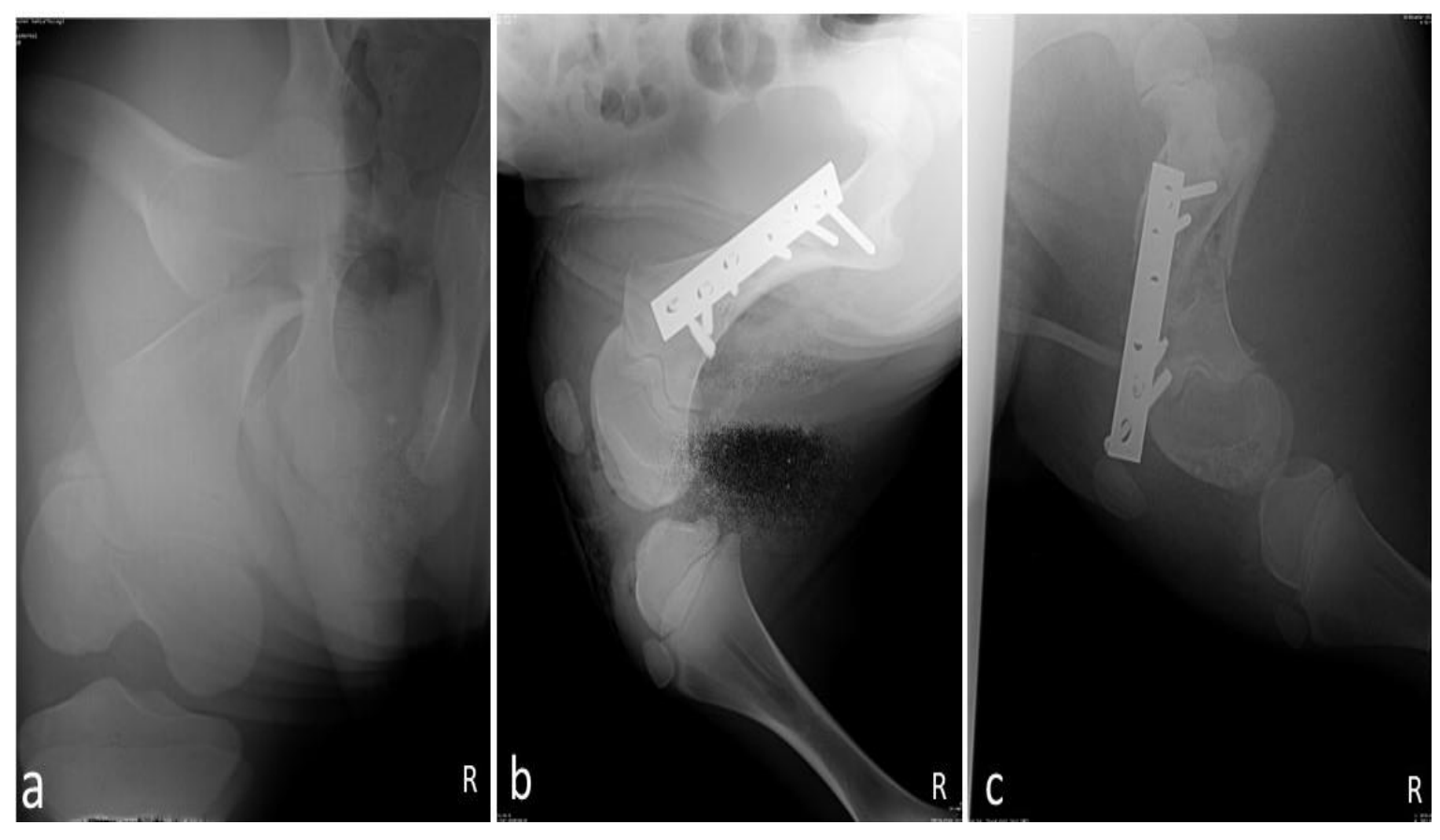

Resim 2. 13 Numaralı olguya ait radyografik görüntüler. (a. Operasyon öncesi, b. Operasyon sonrası c. 35. gün) Figure 2. Radigraphic view of case 13. (a. Preoperatively, b. Postoperatively, c. Postoperative 35. day)

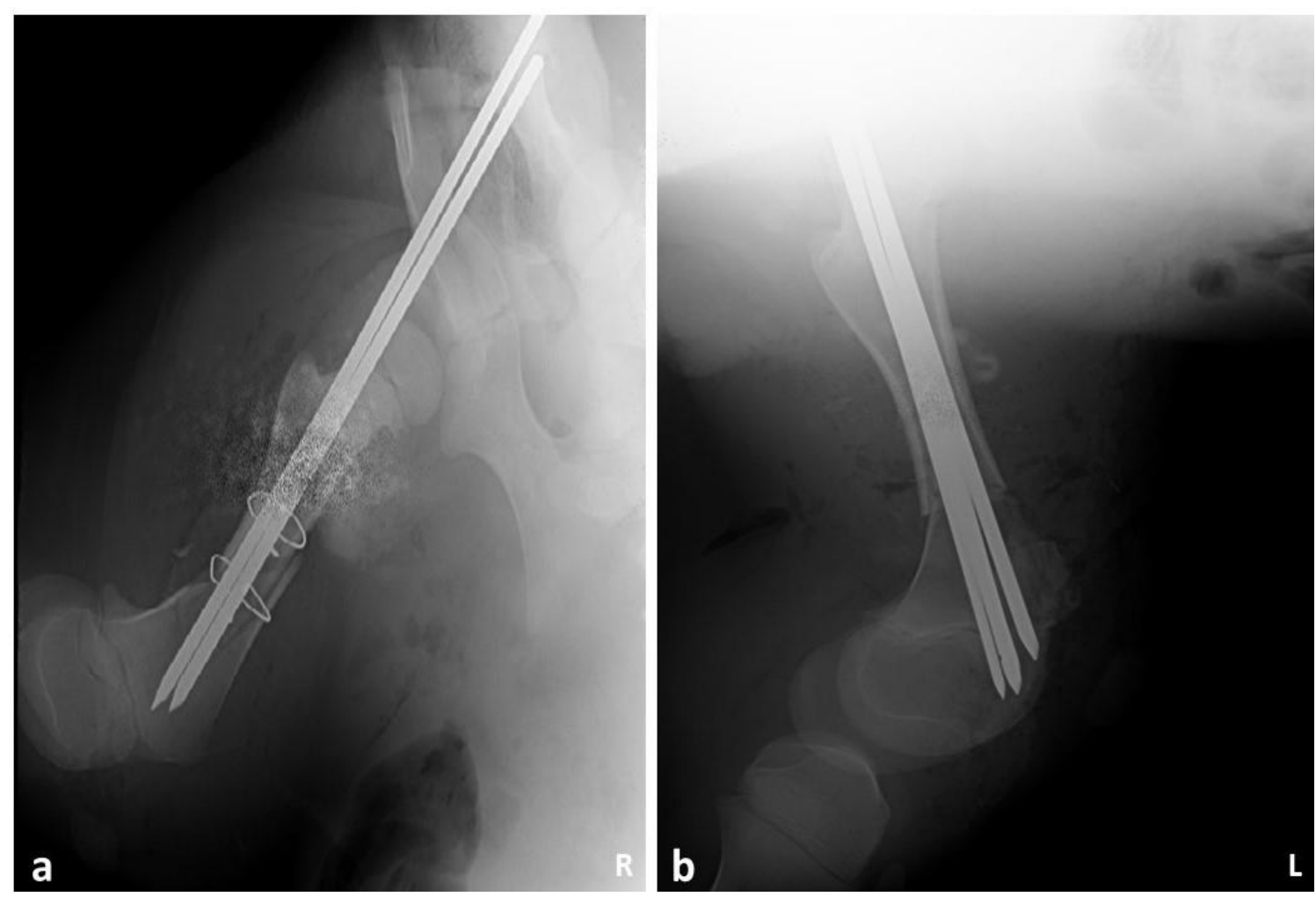

Resim 3. 4 ve 10 numaralı olgulara ait post-operatif kontrol grafileri. (a. 4 numaralı olgu, b. 10 numaralı olgu) Figure 3. Post-operative control radiograms for cases 4 and 10. (a. Case number 4, b. Case number 10) 
Tablo 1. Olguların ırk, yaş cinsiyet, kırık lokalizasyonu, sağaltım seçenekleri.

Table 1. Age, gender, fracture localization and treatment options of cases.

\begin{tabular}{|c|c|c|c|c|c|c|c|c|}
\hline Olgu & Irk & Yaş & Cinsiyet & Kırık Sebebi & Kırık Şekli ve Bölgesi & Sağaltım & $\begin{array}{l}\text { Ekstremiteyi } \\
\text { kullandığı } \\
\text { gün }\end{array}$ & Sonuç \\
\hline 1 & $S$ & $2 \mathrm{~A}$ & $\mathrm{D}$ & Düşme & Suprakondüler kirik & $\begin{array}{l}2 \text { adet } 4 \mathrm{~mm} \text {, } \\
1 \text { adet } 2 \mathrm{~mm} \\
\text { steinman pin }\end{array}$ & 8 & Ulaşılamadı \\
\hline 2 & $S$ & $15 \mathrm{G}$ & $\mathrm{E}$ & Güç doğum & Orta diafizer oblik kırık & $\begin{array}{l}2 \text { adet } 4 \mathrm{~mm} \text {, } \\
1 \text { adet } 2 \mathrm{~mm} \\
\text { steinman pin }\end{array}$ & 2 & - \\
\hline 3 & $\mathrm{E}$ & $5 \mathrm{G}$ & $\mathrm{D}$ & Güç doğum & Suprakondüler kırık & $\begin{array}{l}2 \operatorname{adet} 4 \mathrm{~mm} \\
\text { steinman pin }\end{array}$ & 3 & + \\
\hline 4 & $\mathrm{E}$ & $1 \mathrm{G}$ & $\mathrm{E}$ & Güç doğum & Orta diafizer oblik kırık & $\begin{array}{l}2 \operatorname{adet} 3 \mathrm{~mm} \\
\text { steinman pin }\end{array}$ & 1 & + \\
\hline 5 & $\mathrm{~s}$ & $10 \mathrm{G}$ & $\mathrm{E}$ & $\begin{array}{l}\text { Mazgal arasına } \\
\text { sikışma }\end{array}$ & Orta diafizer oblik kırık & $\begin{array}{c}\text { Hasta sahibi } \\
\text { operasyonu } \\
\text { kabul etmedi }\end{array}$ & - & / \\
\hline 6 & $S$ & $10 \mathrm{G}$ & $\mathrm{D}$ & Tekmelenme & Suprakondüler kırik & $\begin{array}{l}\text { Hasta sahibi } \\
\text { operasyonu } \\
\text { kabul etmedi }\end{array}$ & - & / \\
\hline 7 & S & $3 G$ & $\mathrm{E}$ & Güç doğum & Orta diafizer oblik kırlk & $\begin{array}{l}2 \text { adet } 4 \mathrm{~mm} \text {, } \\
1 \text { adet } 2 \mathrm{~mm} \\
\text { steinman pin }\end{array}$ & 2 & + \\
\hline 8 & $\mathrm{~s}$ & $12 \mathrm{G}$ & $\mathrm{E}$ & Düşme & Orta diafizer parçalı kırı & $\begin{array}{c}\text { Hasta sahibi } \\
\text { operasyonu } \\
\text { kabul etmedi }\end{array}$ & - & / \\
\hline 9 & ES & $20 \mathrm{G}$ & $\mathrm{E}$ & Güç doğum & Suprakondüler kırık & $\begin{array}{l}2 \text { Adet } 3 \mathrm{~mm} \\
\text { steinman pin }\end{array}$ & 3 & + \\
\hline 10 & $\mathrm{ED}$ & $2 \mathrm{G}$ & $\mathrm{E}$ & Güç doğum & $\begin{array}{c}\text { Orta diafizer transversal } \\
\text { kırk }\end{array}$ & $\begin{array}{l}2 \text { adet } 4 \mathrm{~mm} \text {, } \\
1 \text { adet } 2 \mathrm{~mm} \\
\text { steinman pin }\end{array}$ & 2 & + \\
\hline 11 & $\mathrm{E}$ & $7 \mathrm{G}$ & $\mathrm{E}$ & $\begin{array}{c}\text { Annesinin yavruyu } \\
\text { ezmesi }\end{array}$ & Distal diafizer oblik kırı & $\begin{array}{l}2 \text { adet } 4 \mathrm{~mm} \text {, } \\
1 \text { adet } 2 \mathrm{~mm} \\
\text { steinman pin }\end{array}$ & 2 & + \\
\hline 12 & ES & $6 \mathrm{~A}$ & $\mathrm{D}$ & Düşme & Orta diafizer parçalı kırık & $\begin{array}{l}2 \text { adet } 4 \mathrm{~mm} \text {, } \\
1 \text { adet } 2 \mathrm{~mm} \\
\text { steinman pin }\end{array}$ & 4 & + \\
\hline 13 & S & $2 \mathrm{G}$ & $\mathrm{E}$ & Güç doğum & Distal diafizer oblik kırık & $\begin{array}{l}2 \mathrm{~mm} \text { plak, } \\
3 \mathrm{~mm} 3 \text { adet } \\
\text { ve } 4.5 \mathrm{~mm} 3 \\
\text { adet vida }\end{array}$ & 1 & + \\
\hline
\end{tabular}

E: Esmer, S: Simental, ES: Esmer-Simental Melezi, ED: Esmer-Doğu Anadolu Kırmızısı Melezi, +: ̇yileşme var, -: İyileşme yok, /: Tedavi denenmedi.

E: Brown Swiss, S: Simmental, ES: Brown Swiss x Simmental crossbred , ED: Brown Swiss x Eastern Anadolian Red crossbred , +: Positive result, -: Negative result, /: No treatment.

\section{TARTIŞMA ve SONUÇ}

Yeni doğan buzağılarda en önemi kirk nedenlerinden biri güç doğum sırasında yapilan hatalı müdahaleler olarak bildirilmiştir (Aksoy ve ark. 2009, Arıcan ve ark. 2013, Durmuş ve ark. 2009, Nichols ve ark. 2010, Ferguson ve ark. 1990, Ferguson 1994, Yanmaz ve ark. 2014). Bunun yanı sıra doğum sonrasında diğer hayvanlar tarafindan tekmelenme, annenin yavrunun ekstremitelerine basmas1, kayma ve düşme (Akin 2014, Arıcan 2013, Bilgili ve ark. 1999, Durmuş ve ark. 2009, Yanmaz ve ark. 2014) transport ve trafik kazalar1 (Akin 2014, Yanmaz ve ark. 2014) gibi nedenler kırık olușumuna yol açmaktadır. Olgularımızdan 7'sinde kırık oluşma sebebi güç doğum sırasındaki kriko kullanımı gibi hatalı müdahaleler olarak belirlenmiş olup diğer olgularda başka sebepler etiyolojide rol oynamakta idi. Bu bulgu ile gerek hasta sahiplerinin gerekse veteriner hekimlerin doğuma müdahale sırasında çok dikkatli olmaları gerektiği ve usulünce girişimlerde bulunmaları gerektiği sonucuna varılmıştır. Doğum sırasında yapilan hatalı manipülasyonların ülke ekonomisine oldukça yüksek oranda zarar verdiği açıkça görülmektedir. Yeni doğan buzağılardaki femur kırklarında femoral arter lasere olabileceğinden yaşamı tehdit edici kanamalarla karşılaşabilir (Anderson 2015). 
Olgularımızdan hiçbirinde şiddetli kanama ile karşılaşılmamış olması femoral arter laserasyonunun olgularımızda oluşmadığı görüşünü uyandırmıştır. Bir çalışmada yeni doğan buzağılarda karşılaşılan femur kırıkları çoğunlukla proksimal epifiz ve distal metafizde şekillendiği ve genellikle transversal ve oblik kirıklar biçiminde görüldüğü bildirilirken (Hoederman ve ark. 2012) Bellon (2011) ise femur diafizindeki kirıkların oblik ve spiral oluştuğunu bildirmiştir. Çalışmamızdaki kırıkların lokalizasyonları incelendiğinde orta diafizer tip ile 7 olguda karşılaşıldı̆̆ı ve bunlardan 4'ünün oblik kırık, 2'sinin parçalı kırık birinin ise transversal kırık şeklinde olduğu görülmüştür. Güç doğuma bağlı şekillenen kırık olgularında orta diafızer kırık fazlalığı dikkatimizi çekmiştir. Kırık tiplerinin lokalizasyonları Hoederman ile uyumlu değil iken (Hoederman ve ark. 2012) oblik kırıkların çok sayıda olması daha önceki çalışmalar (Bellon ve Mulon 2011, Firat 2007) ile örtüșür nitelikte bulunmuştur. Yenidoğan buzağılarda femur kırıklarının sağaltımında birçok farklı yöntem önerilmektedir (Bellon ve Mulon 2011, Nichols ve ark. 2010). Yaş, vücut ağırlığ1, kırık konfigürasyonu ve ekonomik değer gibi etkenler sağaltım yönteminin seçilmesinde önemli rol oynar (Anderson ve Miesner 2015, Nicholas ve ark. 2010). Konservatif sağaltım genellikle başarılı olmamaktadır (Hoederman ve ark. 2012). Kliniğimize getirilen olgular incelendiğinde ve ekonomik değerleri göz önüne alındığında femur kırıklarının bandaj ile iyileşme şansının oldukça düşük olduğu da dikkate alınarak olgularımızın 10’u operatif olarak sağaltılmış olup 3 olguda hasta sahipleri müdahaleyi kabul etmemişlerdir. Postoperatif dönemde bir hasta sahibine ulaşılamazken diğer olguların 8'inde sağaltımdan başarılı sonuç alınmış, bir olgudan post-operatif bilgi alınamamış ve 1 olgu da ise tatminkâr sonuç elde edilememiștir. Yeni doğan buzağıların femur kırıklarında operasyon ile başarılı sonuçlar alındığı ve bu yöntemin mutlaka değerlendirilmesi gerektiği düşünülmektedir.

İntramedullar pin uygulamasının maliyeti düşük, uygulanması ve çıkarılması kolay aynı zamanda kısa sürede gerçekleştirilmesi ile epifizer plağa en az düzeyde zarar vermesi gibi avantajları vardır. Rotasyonel stabilizasyonun zayıf olması, endosteal kallus oluşumuna olumsuz etki yapması (Bellon ve Mulon 2011, Durmuş ve ark. 2009) ile pin migrasyonu dezavantajlarıdır. Buzağılarda distal diafizer kırıkların sağaltımında İM pinleme yapmış ve oldukça başarılı sonuçlar almıştır (Bellon ve Mulon 2011, Nicholas ve ark. 2010). Olgularımızdan 9'unda steinman demet pinleme yöntemi kullanılmıştır. Olguların 6'sında 2 adet 4 $\mathrm{mm}$ ve bir adet $2 \mathrm{~mm}$ steinman pin kullanılmıştır.
Demet pinleme gerçekleştirdiğimiz olgularımızdan hiç birinde belirtilen dezavantajlar ile karşılaşılmamış olup düşük maliyet ve uygulama kolaylığı açısından son derece kullanışlı bulunmuştur. Operasyon sirasında genellikle buzağıların $10 \mathrm{~mm}$ çapında medullar kanala sahip oldukları görülmüss olup operasyon planlaması yapılırken bu verinin dikkate alınması gerektiği sonucuna ulaşılmıştır.

Plaka uygulamasinın diğer yöntemlere göre daha fazla doku hasarı oluşturduğu ve periosteal dolaşıma zarar verdiği bildirilmektedir (Durmuş ve ark. 2009). Yeni doğan buzağılarda femoral kemiğin yumuşak olması plaka osteosentezindeki en büyük endişelerden bir tanesidir. Çünkü yumuşak neonatal kemik vida gevşemesine predispozisyon yaratabilir ve sonrasinda fiksasyonda instabilite ile karşılaşılabilir (Hoederman ve ark. 2012). Femurun distaline lokalize olmuş kırıklarda, kırık hattının ekleme yakın olması, distal fragmentin kemiğin corpus'una oranla oldukça geniş olması, distal fragmentin spongioz kemik dokudan oluşması gibi nedenler ile stabilizasyon problemi sık yaşanır; ve bu nedenlerle de buzağılarda distal femur kiriklarinın prognozu genellikle olumsuz olarak kabul edilmektedir (Akin ve ark. 2014, Bellon ve Mulon 2011, Ferguson 1994, Ferguson ark. 1990). Distal diafizer kırıklı bir olgumuzda uyguladığımız plaka osteosentezinde distal vidalarda gevşeme ile karşılașılmış olup olgunun sınırlı hareketlerine izin verilmiş ve kallus oluşumuna kadar plaka çıkarılmamış sonrasında çıkarma işlemi gerçekleştirilerek olgunun ayağını kullanabildiği görülmüştür. $\mathrm{Bu}$ vida gevşemesinin literatürlerde belirtilen nedenlerden kaynaklandığ1 düşünülmektedir.

Sonuç olarak, yeni doğan buzağılarda oldukça yüksek insidansta karşılaşılan femur kırıklarının lokalizasyonu ve şekli belirlenmiş olup sağaltımları gerçekleştirilmiştir. Özellikle diafizer femur kırıklarının sağaltımında kullandığımız demet pinleme tekniğinden başarılı sonuçlar elde edilmiştir. Bunun yanı sıra kilitli intramedullar pin tekniği gibi yöntemleri deneme şansımız olmamış, plaka osteosentezi ise çok yetersiz sayıda kalmıştır. Demet pinleme tekniği ile diafizer femur kırıklarının başarılı şekilde sağaltılmasının yanı sıra diğer kırık tiplerinde farklı yöntemlerin ilerideki yapılacak çalışmalar ile netlik kazandırılması görüşüne varılmıştır. Ayrıca buzağılardaki femur kirıklarının \%53.84 oranında güç doğumlarda bilinçsizce yaklaşıma bağlı olarak insan kaynaklı geliştiği tespit edilmiş ve yetiştiricilerin bu konuda bilgilendirilmesi gerektiği kanaatine varılmıştır. 


\section{TEŞEKKÜRLER}

Çalışmanın her aşamasında emeği geçen Sayın Prof. Dr. Özgür AKSOY'a teşekkür ederim.

\section{KAYNAKLAR}

Aithal HP, Singh GR, Hoque M, Maiti SK, Kinjavdekar P, Amarpal, Pawde AM, Setia HC. The use of a circular external skeletal fixation device fort he management of long bone osteotomies in large ruminants: An experimental study. J Vet Med. 2014; A 51: 284-293.

Akın İ, Gülaydın A, Şen ZB. Yeni Doğan Bir Buzağıda Distal Diafizer Femur Kirığ Olgusunun Kilitli Küntscher Çivisi ile Sağaltımı. Animal Health Prood and Hyg. 2014; 3 (2): 320-322.

Akin İ. Comparison of the Mid-Sahft Bone Geometry Between Fractured and Nonfractured Femora in Newborn Calves. Acta Sientiae Veterinariae. 2014; 42: 1186.

Aksoy O, Özaydın İ, Kılıç E, Öztürk S, Güngör E, Kurt B, Oral H. Evaluation of fractures in calves due to forced extraction during dystocia: 27 cases (2003-2008). Kafkas Univ Vet Fak Derg. 2009; 15 (3): 339-344.

Anderson DE, Miesner MD. Surgical management of orthopedic and musculoskeletal diseases of feedlot calves. Vet Clin Food Anim. 2015; 31 (3) : 425-439.

Arican M, Erol H, Essin E, Parlak K. A retrospective sudy of fractures in neonatal calves: 181 cases (2002-2012). Pak Vet J. 2013; 34 (2): 247-250.

Bellon J, Mulon P. Use of novel intramedullary nail for femoral fracture repair in calves: 25 cases (2008-2009). JAVMA. 2011; 238 (11): 1490-1496.

Bilgili H, Kürüm B, Olcay B. Buzağılarda uzun kemik kırıklarının İlizarov tekniği ile sağlatım olanaklarının araştırılması. Ankara Üniv Vet Fak Derg. 1999; 46; 299-308.

Durmuş AS, Karabulut E, Sağlıyan E. Yenidoğan Bir Buzağıda Suprakondiler Femur Kırı̆g Olgusu ve Operatif Sağaltımı. F.Ü. Sağ. Bil. Vet. Derg. 2009; 23 (2): 119122.

Ferguson GJ, Dehghani S, Petrali EH. Fractures of the femur in newborn calves. Can Vet J. 1990; 31: 289-291.
Ferguson JG. Femoral fractures in the newborn calf: Biomechanics and etiological considerations for practitiners. Can Vet J. 1994; 35: 626-630.

Firat $\mathbf{O}$. The cases of fractures in calves referred in our clinic and treatment possibilities. Adnan Menderes Üniveristesi Sağlık Bilimleri Enstitüsü Yüksek Lisans Tezi. 2007.

Gang1 M Grulke S, Serteyn D, Touati K. Retrospective study of 99 cases of bone fratures in cattle treated by external coaptation or confinement. Veterinary Record. 2006; 158: 264-268.

Görgül OS, Seyrek-İntaş D, Çelimli N, Çeçen G, Salcı H, Akın İ. Buzağılarda Kırık Olgularının Değerlendirilmesi: 31 olgu(19962003). Veteriner Cerrahi Derneği Dergisi. 2004; 10 (3-4): 16-20.

Hoederman M, Gedet P, Ferguson SJ, SauterLouis C, Nuss K. In-vitro comparison of LC-DCP and LCP-constructs in the femur of newborn calves- a pilot study. BMC Veterinary Research. 2012; 8: 139.

Junior OS, Faleiros RR, Alves GES, Casas EBL, Rodrigues LB, Loiacono BZ, Cassou F. Failures in the use of polyacetal and polyamide in the form of intramedullary interlocking nail for immobilization of induced femoral fracture in young cattle. Ciencia Rural. 2010; 40 (4): 907-912.

Nichols S, Anderson DE, Miesner MD, Kewman KD. Femoral diaphysis fractures in cattle: 26 cases (1994-2005. Aust Vet J. 2010; 88 (1-2): 39-44.

Öztaş E, Avki S. Evaluation of Acrylic Pin External Fixation (APEF) System in Metacarpal Fractures of Newborn Calves: Cheap But Effective? Kafkas Univ Vet Fak Derg. 2015; 21 (3) 433-436.

Yanmaz LE, Kaya M, Doğan E, Okumuş Z. Sığır ve buzağılardaki kırık olgularının değerlendirilmesi. YYU Vet Fak Derg. 2014; 25 (1): 23-26. 